\title{
PATTERN OF ANTIMICROBIAL RESISTANCE IN CLINICAL ISOLATES OF ACINETOBACTER SPECIES AT A TERTIARY LEVEL HEALTH CARE FACILITY IN NORTHERN INDIA
}

Pooja Singla, Rama Sikka, Antariksh Deep, Seema, Uma Chaudhary

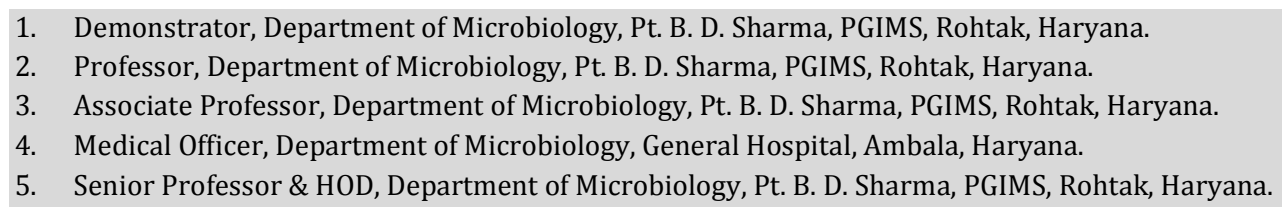

\section{CORRESPONDING AUTHOR}

Dr. Pooja Singla,

Demonstrator, Dept. of Microbiology,

Pt. B. D. Sharma, PGIMS, Rohtak, Haryana

E-mail: pjsingla3@gmail.com

Ph: 00919813078178.

ABSTRACT: BACKGROUND: Multi drug resistant Acinetobacter species is a rapidly emerging pathogen in health care settings and has limited the options for effective treatment. It is increasingly reported as the cause of outbreaks and nosocomial infections such as blood-stream infections, ventilator-associated pneumonia, urinary tract infections and wound infections. AIM: The present study was undertaken to isolate and identify the multi drug resistant (MDR) and extensively drug resistant (XDR) Acinetobacter species. DESIGN AND SETTINGS: This is a prospective study conducted over a period of two years (September 2009 to August 2011) in a tertiary care hospital. Clinical samples were collected from both indoor and outdoor patients, irrespective of age and sex. MATERIALS AND METHODS: Three hundred non duplicate clinical isolates of Acinetobacter species were processed for species identification by standard Microbiological procedures. Antimicrobial susceptibility of these isolates was performed by Kirby-Bauer disc diffusion method. RESULTS: Of the 300 isolates, 224 (74.6\%) were identified as A. baumannii followed by A. lwoffii $73 / 300$ (24.3\%) and A. haemolyticus 3/300 (1\%). Majority of the isolates were recovered from ICU patients 183/300 (61\%), followed by patients admitted in wards $93 / 300(31 \%)$ and $24 / 300(8 \%)$ isolates were from outdoor patients. Out of 300, 153 (51\%) isolates were XDR and 11\% were MDR. Only about 10\% of the isolates were sensitive to $\beta$-lactams and $30-40 \%$ of the strains were sensitive to aminoglycosides and fluoroquinolones. None of the isolate was resistant to cefoperazone sulbactam, ceftriaxone sulbactam and polymyxins. Statistically significant difference ( $p$ value $<0.001$ ) was noticed between antibiotic resistance of A. baumannii and A. lwoffii. CONCLUSION: The increasing trends towards antibiotic resistance reflect the extensive use of antibiotics in hospitals which in turn exerts selective pressure on Acinetobacter in hospital environment. Therefore, by judicial use of antibiotics these drug resistant nosocomial Acinetobacter infections can be minimized to some extent.

KEYWORDS: Acinetobacter, Multi drug resistant, Extensively drug resistant, Nosocomial, Carbapenems

INTRODUCTION: Acinetobacter baumannii is a gram negative ubiquitous pathogen which is capable of causing both community acquired and health care associated infections. It causes a 
wide range of clinical infections such as pneumonia, blood stream infections, urinary tract infections, wound infections and meningitis especially in patients admitted in intensive care units. Resistance to all major classes of antimicrobial agents has increased substantially in the members of the genus Acinetobacter, especially in A. baumannii. It is often difficult to distinguish between the colonization and the infection with this organism and hence attribute the exact morbidity and mortality associated with infections due to this organism. The common risk factors associated with infections due to A. baumannii include prolonged hospitalization, admission to intensive care units, recent surgical procedures and exposure to antimicrobial agents. The species other than A. baumannii such as A. lwoffii, A. johnsonii, A. junii and A. haemolyticus are less frequently involved in nosocomial infections, and are generally not highly resistant to antimicrobial agents. ${ }^{1}$ For the present study, multi drug resistant (MDR) Acinetobacter spp. shall be defined as the isolate resistant to at least three classes of antimicrobial agents- all penicillins and cephalosporins (including inhibitor combinations), fluoroquinolones and aminoglycosides. Extensively drug resistant (XDR) Acinetobacter spp. shall be the isolate which is resistant to the three classes of antimicrobials described above (MDR) and shall also be resistant to carbapenems. Finally, pan drug resistant (PDR) Acinetobacter spp. shall be the XDR Acinetobacter isolate which is also resistant to polymyxins and tigecycline. Due to high antimicrobial resistance shown by this microorganism, less therapeutic options are available leading to high mortality rate and longer hospital stay. ${ }^{2}$ In view of the increasing challenges posed by this organism in health care settings, the present study was planned to determine the prevalence of MDR, XDR and PDR Acinetobacter isolates in our hospital.

MATERIALS AND METHODS: SAMPLE COLLECTION: The present prospective study was conducted in the Department of Microbiology at a tertiary level teaching health care facility over a period of two years (September 2009 to August 2011). Three hundred non-duplicate Acinetobacter isolates, recovered from the urine, pus, blood, respiratory samples such as endotracheal aspirates, bronchoalveolar lavage (BAL), CSF, high vaginal swabs and various body fluids were included in the study. The clinical specimens were collected from both indoor and outdoor patients irrespective of age and gender.

ISOLATION AND IDENTIFICATION OF ACINETOBACTER SPECIES: For the isolation of Acinetobacter spp., the clinical samples were inoculated onto blood agar and MacConkey agar. After overnight incubation at $37^{\circ} \mathrm{C}$, the suspected colonies were further processed for identification of Acinetobacter species by Gram staining, oxidase test, hanging drop and by other standard biochemical tests. Speciation of the Acinetobacter isolates was done as per the biochemical tests described in the table $1 .^{3}$

ANTIMICROBIAL SUSCEPTIBILITY TESTING: The antimicrobial susceptibility testing of all the 300 Acinetobacter isolates was carried out by Kirby-Bauer disc diffusion method on MuellerHinton agar medium and results were interpreted as per the Clinical and Laboratory Standards Institute guidelines. ${ }^{4}$ Antimicrobial discs used in the study were procured from Hi-media Laboratories, Mumbai, India. Following antibiotic discs were put up with the concentration of the compound mentioned in the parenthesis: ceftazidime $(30 \mu \mathrm{g})$, cefepime $(30 \mu \mathrm{g})$, ceftriaxone $(30 \mu \mathrm{g})$, cefotaxime $(30 \mu \mathrm{g})$, amoxycillin/clavulanic acid $(20 \mu \mathrm{g} / 10 \mu \mathrm{g})$, piperacillin/tazobactam $(100 \mu \mathrm{g} / 10 \mu \mathrm{g})$, ticarcillin/clavulanic acid $(75 \mu \mathrm{g} / 10 \mu \mathrm{g})$, imipenem $(10 \mu \mathrm{g})$, meropenem $(10 \mu \mathrm{g})$, gentamicin $(10 \mu \mathrm{g})$, amikacin $(30 \mu \mathrm{g})$, netilmicin $(30 \mu \mathrm{g})$, ciprofloxacin $(5 \mu \mathrm{g})$, doxycycline $(30 \mu \mathrm{g})$, 
cotrimoxazole $(15 \mu \mathrm{g})$, polymyxin B (300 units), colistin $(10 \mu \mathrm{g})$, cefoperazone/sulbactam $(75 \mu \mathrm{g} / 15 \mu \mathrm{g})$, ceftriaxone/sulbactam $(30 \mu \mathrm{g} / 15 \mu \mathrm{g})$. Escherichia coli ATCC 25922 strain was employed as a control strain.

STATISTICAL ANALYSIS: For comparison of two or more set of variables, p value was calculated by using SPSS version 19 . If the $p$-value was $<0.05$, it was considered significant.

RESULTS: A total of 300 non-duplicate, non-consecutive Acinetobacter isolates were processed for species identification, antimicrobial susceptibility testing and to know the MDR, XDR and PDR pattern of these isolates. A. baumannii was the commonest species isolated 224/300 (74.6\%), followed by A. lwoffii 73/300 (24.3\%) and A. haemolyticus 3/300 (1\%). The pattern of distribution of Acinetobacter species from various clinical samples is reflected in Table 2 . Majority of the isolates were recovered from the patients admitted in ICUs 183/300 (61\%), followed by those admitted in the wards $93 / 300$ (31\%). About $8 \%$ of the isolates recovered were from the outdoor patients. The male to female ratio among patients with Acinetobacter infection was 1.7:1 and the most common age groups involved were less than ten years 71/300 (23.6\%), patients of more than 60 years 57/300 (19\%) and age group between 20-30 years $50 / 300(16.6 \%)$. The antimicrobial susceptibility pattern of A. baumannii and A. lwoffii is shown in table 3. On comparing the antibiotic resistance between Acb complex and A. lwoffii significant difference in terms of $p$ value $(<0.001)$ was observed for most of the antibiotics. Out of 300 Acinetobacter isolates, 153 (51\%) were XDR as these were resistant to atleast one of the carbapenems, aminoglycosides, fluoroquinolones, $\beta$-lactams and $\beta$-lactam- $\beta$-lactamase inhibitor combinations. About $11 \%$ of the isolates were resistant to other group of antimicrobial agents except carbapenems so, these were categorized as MDR isolates. None of the isolates recovered was resistant to polymyxin B, colistin, cefoperazone/sulbactam and ceftriaxone/sulbactam. Thus, there was no isolate, which was found to be PDR. Acinetobacter isolates recovered from ICU patients were found to be more drug resistant than those isolated from ward and outdoor patients. The antimicrobial susceptibility pattern of various Acinetobacter species from different hospital areas is described in table 4.

DISCUSSION: Of all the species in the genus, A. baumannii is the main species associated with outbreaks of nosocomial infections in ICUs, probably related to the increasingly greater quantity of broad spectrum antimicrobials used. The rate of isolation of Acinetobacter species from our study was $8.7 \%$. Various other studies have reported the rate of isolation varying from $4.25 \%$ to 20.1\% (Mindolli et al; 2010, Lahiri et al; 2004, and Behera et al; 2011).5, 6, 7 This variation can be attributed to the varying prevalence rates of different Acinetobacter species in the hospital environment and the community in different geographical areas. However, A. baumannii is seldom recognized as a true environmental organism. Like many other previous studies the species most commonly isolated from the clinical samples in our institution was A. baumannii, followed by A. lwoffii and A. haemolyticus (Mindolli et al; 2010, Rubina et al; 2009, Oberoi et al; 2009).5,8,9 The most common infection caused by Acinetobacter species in our study was the blood stream infections followed closely by the hospital acquired pneumonia.

In current study, ICU stay and previous exposure to antimicrobial agents was found to be significant risk factors for the Acinetobacter infections as majority (61\%) of the isolates were recovered from ICU patients. The past medical records of more than $70 \%$ of the indoor patients of our study showed that they were treated with either of extended spectrum cephalosporins or 
fluoroquinolones before getting admitted to this health care facility. This is concurrent with many studies which have identified exposure to antimicrobial agents and ICU stay as a potential risk factors for multidrug resistant and pan-drug resistant strains (Vincent et al; 2009, Lee Sang oh et al; 2004). ${ }^{10,11}$

We noticed a high level of resistance in Acinetobacter species to most of the antibiotics except piperacillin tazobactam and imipenem which were found to be effective in $69 \%$ and $65 \%$ of the Acinetobacter strains respectively. Only about $10 \%$ of the isolates were sensitive to $\beta$ lactams and $30-40 \%$ of the strains were sensitive to aminoglycosides and fluoroquinolones. Susceptibility for cotrimoxazole and doxycycline was found in about $20 \%$ of the strains. Cefoperazone/sulbactam and ceftriaxone/sulbactam were found to be most effective combinations as no isolate showed resistance to these. Taneja et al; 2012 showed that the resistance of Acinetobacter to gentamicin, amikacin and ciprofloxacin was 79.5\%, 73.2\% and $72.8 \%$ respectively. ${ }^{12}$ Shareek et al; 2012 reported that only $25 \%$ of the strains were sensitive to carbapenems, $10-15 \%$ of the strains were sensitive to $\beta$-lactams and $20-28 \%$ of the strains were sensitive to amikacin, ciprofloxacin and cotrimoxazole. ${ }^{13}$ Other studies have also shown similar results for different antimicrobial agents. ${ }^{14,15}$ Resistance to polymyxins has also been reported by many authors ${ }^{12,16}$ but in our study we did not notice any resistance to these antibiotic.

One pleasant fact from our study was that the isolates responsible for the community acquired infections were less resistant to the commonly used antimicrobial agents as compared to the nosocomial strains ( $\mathrm{p}$ value $<0.01$ ). A. baumannii was found to be more drug resistant than $A$. lwoffii in our study. Significant statistical difference ( $p$ value $<0.001$ ) was observed between these Acinetobacter species to almost all antimicrobial agents used in the study. Shareek et al; 2012 also reported the similar results. ${ }^{13}$ The current study showed $51 \%$ of the Acinetobacter isolates were XDR and $11 \%$ as MDR. Taneja et al also reported $41.5 \%$ and $22.3 \%$ of the Acinetobacter isolates as MDR and XDR respectively. ${ }^{12}$

CONCLUSION: Acinetobacter baumannii has already been notified by the Infectious Disease Society of America as a "red alert" pathogen. The high prevalence of multidrug resistant and extensively drug resistant Acinetobacter species in our hospital only underscores the urgent need for instituting control measures to limit the spread of this troublesome nosomial pathogen in various hospital areas. In this direction, the Hospital Infection Control Committee has organized sensitization programmes regarding the hand hygiene and enhanced environmental cleaning activities in our institute. The other areas of attention in future include identification of the colonized patients and their environment and developing a customized antibiotic management programme based upon antimicrobial susceptibility of local bacterial isolates, for judicious use of "at risk" antibiotics.

\section{REFERENCES}

1. Peleg AY, Seifert H, Paterson DL. Acinetobacter baumannii: Emergence of a successful pathogen. Clin Microbiol Rev 2008;21(3):538-82.

2. Manchanda V, Sanchaita S, Singh NP. Multidrug resistant Acinetobacter. J Global Infect Dis 2010; 2:291-304.

3. The nonfermentative gram-negative bacilli. In: Winn Jr. WC, Allen SD, Janda WM, Koneman EW, Procop GW, Schreckenberger PC, et al, editors. Koneman's color Atlas and Textbook of Diagnostic Microbiology, $6^{\text {th }}$ ed. Philadelphia: Lippincott Williams and Wilkins; 2006.p.303-391. 
4. Clinical and Laboratory Standards Institute. Performance standards for antimicrobial disk susceptibility tests: approved standard. 9th ed. CLSI document M2-A9, Vol 26(1). Wayne, PA; 2006.

5. Mindolli PB, Salmani MP, Vishwanath G, Manumanthappa AR. Identification and speciation of Acinetobacter and their antimicrobial susceptibility testing. Al Ameen J Med Sci 2010; 3:345-9.

6. Lahiri KK, Mani NS, Purai SS. Acinetobacter spp. as nosocomial pathogen: clinical significance and antimicrobial sensitivity. Med J Armed Forces India 2004;60:7-10.

7. Behera B, Mathur P. High levels of antimicrobial resistance at a tertiary trauma care centre of India. Indian J Med Res 2011; 133:343-5.

8. Lone R, Shah A, Kadri SM, Lone S, Faisal S. Nosocomial multidrug resistant Acinetobacter infections-clinical findings, risk factors and demographic characteristics. Bangladesh J Med Microbiol 2009; 3:34-8.

9. Oberoi A, Aggarwal A, Lal M. A decade of an underestimated nosocomial pathogenAcinetobacter in a tertiary care hospital in Punjab. JK Sci 2009; 11:24-6.

10. Vincent JL, Rello J, Marshall J, Silva E, Anzueto A, Martin DC et al. International study of the prevalence and outcomes of infection in intensive care units. JAMA 2009; 302:23239.

11. Lee SO, Kim NJ, Choi SH, Kim TH, Chung JW, Woo JH et al. Risk factors for the acquisition of imipenem resistant Acinetobacter baumannii: a case-control study. Antimicrob Agents Chemother 2004; 48:224-8.

12. Taneja N, Singh G, Singh M, Sharma M. Emergence of tigecycline and colistin resistant Acinetobacter baumannii in patients with complicated urinary tract infections in north India. Indian J Med Res 2011; 133:681-4.

13. Shareek, Sureshkumar D, Ramgopalakrishnan, Ramasubramanian V, Abdul Ghafur K, Thirunarayanan MA. Antibiotic sensitivity pattern of blood isolates of Acinetobacter species in a tertiary care hospital: A retrospective analysis. Am J Infect Dis 2012; 8:6569.

14. Goel N, Chaudhary U, Aggarwal R, Kiran B. Antibiotic sensitivity pattern of gram negative bacilli isolated from the lower respiratory tract of ventilated patients in the intensive care unit. Indian J Crit Care Med 2009; 13:148-151.

15. Karthika RU, Rao RS, Sahoo S, Shashikala P, Kanungo R, Jayachandran S, et al. Phenotypic and genotypic assays for detecting the prevalence of metallo- $\beta$-lactamases in clinical isolates of Acinetobacter baumannii from a South Indian tertiary care hospital. J Med Microbiol 2009; 58:430-5.

16. Ko KS, Suh JY, Kwon KT, Jung SI, Park KH, Kang CI et al. High rates of resistance to colistin and polymyxin B in subgroups of Acinetobacter baumannii isolates from Korea. J Antimicrob Chemother 2007; 60:1163-7.

TABLE 1: Identification scheme for differentiation of Acinetobacter species

\begin{tabular}{|c|c|c|c|c|c|c|c|}
\hline \multirow{2}{*}{\multicolumn{2}{|c|}{ Haemolysis on sheep blood agar }} & \multicolumn{2}{|c|}{ A. baumannii } & \multicolumn{2}{|c|}{ A. lwoffii } & \multicolumn{2}{|c|}{ A. haemolyticus } \\
\hline & & \multicolumn{2}{|c|}{-} & \multicolumn{2}{|c|}{ - } & \multicolumn{2}{|c|}{+} \\
\hline \multicolumn{2}{|c|}{ Hugh-Leifson $(0 / F)$ glucose oxidation } & \multicolumn{2}{|c|}{+} & \multicolumn{2}{|c|}{-} & \multicolumn{2}{|c|}{+} \\
\hline \multicolumn{2}{|c|}{ Citrate utilization test } & \multicolumn{2}{|c|}{+} & \multicolumn{2}{|c|}{ - } & \multicolumn{2}{|c|}{-} \\
\hline \multicolumn{2}{|c|}{ Arginine dihydrolase test } & \multicolumn{2}{|c|}{+} & \multicolumn{2}{|c|}{-} & \multicolumn{2}{|c|}{-} \\
\hline \multicolumn{2}{|c|}{ Gelatin liquification } & & \multicolumn{2}{|c|}{-} & \multicolumn{2}{|c|}{+} \\
\hline Growth at $37^{\circ} \mathrm{C}$ & Growth at $44^{\circ} \mathrm{C}$ & + & + & + & - & + & - \\
\hline $\begin{array}{l}\text { Susceptibility to } \\
\text { Penicillin }\end{array}$ & $\begin{array}{l}\text { Susceptibility to } \\
\text { Chloramphenicol }\end{array}$ & - & - & + & + & - & - \\
\hline
\end{tabular}


TABLE 2: Specimen sources of different Acinetobacter species

\begin{tabular}{|c|c|c|c|c|}
\hline Clinical sample & $\begin{array}{c}\text { A. baumannii } \\
\text { number (\%) }\end{array}$ & $\begin{array}{c}\text { A. lwoffii } \\
\text { number (\%) }\end{array}$ & $\begin{array}{c}\text { A. haemolyticus } \\
\text { number (\%) }\end{array}$ & $\begin{array}{c}\text { Total } \\
\text { Number (\%) }\end{array}$ \\
\hline Blood & $64(28.5)$ & $24(32.8)$ & $2(66.6)$ & $90(30)$ \\
\hline Respiratory samples & $51(22.7)$ & $26(35.6)$ & 0 & $77(25.6)$ \\
\hline Pus & $38(16.9)$ & $6(8.2)$ & $1(33.3)$ & $45(15)$ \\
\hline Urine & $35(15.6)$ & $7(9.5)$ & 0 & $42(14)$ \\
\hline Stool & $18(8)$ & $5(6.8)$ & 0 & $23(7.6)$ \\
\hline Body fluids & $9(4)$ & $2(2.7)$ & 0 & $11(3.6)$ \\
\hline CSF & $2(0.8)$ & 0 & 0 & $2(0.6)$ \\
\hline Throat swabs & $3(1.3)$ & $2(2.7)$ & 0 & $5(1.6)$ \\
\hline HVS & $4(1.7)$ & $1(1.3)$ & 0 & $5(1.6)$ \\
\hline Total & 224 & 73 & 3 & 300 \\
\hline
\end{tabular}

*Figures in parenthesis indicate percentage

TABLE 3: Comparison of the antimicrobial susceptibility of A. baumannii and A. lwoffii

\begin{tabular}{|c|c|c|c|}
\hline Antimicrobial drugs & $\begin{array}{ll}A . & \text { baumannii }(\mathrm{n}=224) \\
& \text { Number }(\%)\end{array}$ & $\begin{array}{l}\text { A. lwoffii }(n=73) \\
\text { Number }(\%)\end{array}$ & p value \\
\hline Amikacin & $63(28.1)$ & 65(89) & $<0.001$ \\
\hline Gentamicin & $40(17.8)$ & 54(73.9) & $<0.001$ \\
\hline Netilmicin & $68(30.3)$ & $67(91.7)$ & $<0.001$ \\
\hline Ciprofloxacin & $47(20.9)$ & $50(68.4)$ & $<0.001$ \\
\hline Cotrimoxazole & $12(5.3)$ & $43(58.9)$ & $<0.001$ \\
\hline Doxycycline & $22(9.8)$ & $33(45.2)$ & $<0.001$ \\
\hline Ceftazidime & $5(2.2)$ & $5(6.8)$ & $<0.05$ \\
\hline Ceftriaxone & $3(1.3)$ & $23(31.5)$ & $<0.001$ \\
\hline Cefotaxime & $2(0.8)$ & $31(42.4)$ & $<0.001$ \\
\hline Cefepime & $10(4.4)$ & $22(30.1)$ & $<0.001$ \\
\hline Piperacillin+tazobactam & $142(63.3)$ & $50(68.4)$ & $>0.05$ \\
\hline Ticarcillin+clavulanic acid & $49(21.8)$ & $60(82.1)$ & $<0.001$ \\
\hline Amoxycillin+clavulanic acid & 9(4) & $34(46.5)$ & $<0.001$ \\
\hline Imipenem & $118(52.6)$ & 69(94.5) & $<0.001$ \\
\hline Meropenem & 81(36.1) & 61(83.5) & $<0.001$ \\
\hline Polymyxin B & $224(100)$ & $73(100)$ & -- \\
\hline Colistin & $224(100)$ & $73(100)$ & -- \\
\hline
\end{tabular}

* Figures in parenthesis indicate percentage of susceptible strains 
TABLE 4: Antimicrobial susceptibility pattern of Acinetobacter species recovered from indoor and outdoor patients

\begin{tabular}{|c|c|c|c|c|c|c|c|c|c|c|c|c|c|c|c|c|}
\hline \multicolumn{2}{|c|}{$\begin{array}{c}\text { Antimicrobi } \\
\text { al } \\
\text { agents }\end{array}$} & 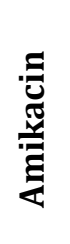 & 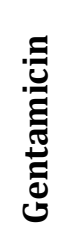 & 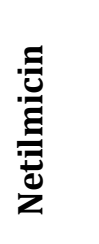 & 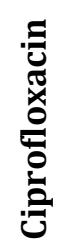 & 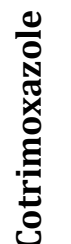 & 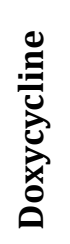 & 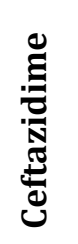 & 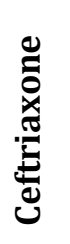 & 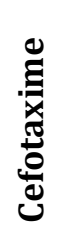 & : & 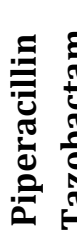 & 窇 & 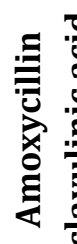 & 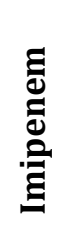 & 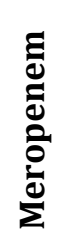 \\
\hline \multirow{3}{*}{ 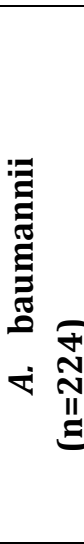 } & $\begin{array}{l}\text { ICU } \\
n=14 \\
5\end{array}$ & $\begin{array}{c}23 \\
(15 \\
)\end{array}$ & $\mathbf{0}$ & $\begin{array}{c}22 \\
(15)\end{array}$ & $\begin{array}{c}1 \\
(0)\end{array}$ & $\mathbf{0}$ & $\mathbf{0}$ & $\begin{array}{c}3 \\
(2)\end{array}$ & $\begin{array}{c}1 \\
(0)\end{array}$ & $\begin{array}{c}1 \\
(0)\end{array}$ & $\begin{array}{c}2 \\
(1)\end{array}$ & $\begin{array}{c}10 \\
8 \\
(74\end{array}$ & $\begin{array}{c}19 \\
(13 \\
)\end{array}$ & 0 & $\begin{array}{c}70 \\
(48 \\
)\end{array}$ & $\begin{array}{c}33 \\
(23 \\
)\end{array}$ \\
\hline & $\begin{array}{l}\text { Indoo } \\
r \\
(n=61 \\
)\end{array}$ & $\begin{array}{c}30 \\
(49 \\
)\end{array}$ & $\begin{array}{c}31 \\
550 \\
)\end{array}$ & $\begin{array}{c}36 \\
(59)\end{array}$ & $\begin{array}{c}35 \\
(57 \\
)\end{array}$ & $\begin{array}{c}3 \\
(5)\end{array}$ & $\begin{array}{c}19 \\
(31 \\
)\end{array}$ & $\begin{array}{c}1 \\
(2)\end{array}$ & $\begin{array}{c}1 \\
(2)\end{array}$ & $\mathbf{0}$ & $\begin{array}{c}7 \\
(11 \\
)\end{array}$ & $\begin{array}{c}29 \\
(48 \\
)\end{array}$ & $\begin{array}{c}24 \\
(40 \\
)\end{array}$ & $\begin{array}{c}6 \\
(10 \\
)\end{array}$ & $\begin{array}{c}37 \\
(61 \\
)\end{array}$ & $\begin{array}{c}39 \\
(64 \\
)\end{array}$ \\
\hline & $\begin{array}{l}\text { OPD } \\
(n=18 \\
)\end{array}$ & $\begin{array}{c}10 \\
(55 \\
)\end{array}$ & $\begin{array}{c}9 \\
(50 \\
)\end{array}$ & $\begin{array}{c}10 \\
(55)\end{array}$ & $\begin{array}{c}11 \\
(61 \\
)\end{array}$ & $\begin{array}{c}9 \\
(50 \\
)\end{array}$ & $\begin{array}{c}3 \\
(17 \\
)\end{array}$ & $\begin{array}{c}1 \\
(6)\end{array}$ & $\begin{array}{c}1 \\
(6)\end{array}$ & $\begin{array}{c}1 \\
(6)\end{array}$ & $\begin{array}{c}1 \\
(6)\end{array}$ & $\begin{array}{c}5 \\
(28 \\
)\end{array}$ & $\begin{array}{c}6 \\
(33 \\
)\end{array}$ & $\begin{array}{c}3 \\
(17 \\
)\end{array}$ & $\begin{array}{c}11 \\
(61 \\
)\end{array}$ & $\begin{array}{c}9 \\
(50 \\
)\end{array}$ \\
\hline \multirow{3}{*}{ 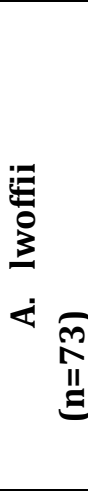 } & $\begin{array}{l}\text { ICU } \\
(n=36 \\
)\end{array}$ & $\begin{array}{c}30 \\
(83 \\
)\end{array}$ & $\begin{array}{l}25 \\
(70 \\
)\end{array}$ & $\begin{array}{c}31 \\
(86)\end{array}$ & $\begin{array}{l}20 \\
(56 \\
)\end{array}$ & $\begin{array}{c}19 \\
(53 \\
)\end{array}$ & $\begin{array}{c}14 \\
(39 \\
)\end{array}$ & $\begin{array}{c}1 \\
(3)\end{array}$ & $\mathbf{0}$ & $\begin{array}{c}4 \\
(11 \\
)\end{array}$ & $\begin{array}{c}5 \\
(14 \\
)\end{array}$ & $\begin{array}{c}22 \\
(61 \\
)\end{array}$ & $\begin{array}{c}27 \\
(75 \\
)\end{array}$ & $\begin{array}{c}15 \\
(42 \\
)\end{array}$ & $\begin{array}{l}34 \\
(94 \\
)\end{array}$ & $\begin{array}{c}27 \\
(75 \\
)\end{array}$ \\
\hline & $\begin{array}{l}\text { Indoo } \\
r \\
(n=31 \\
)\end{array}$ & $\begin{array}{c}29 \\
(93 \\
)\end{array}$ & $\begin{array}{l}24 \\
(78 \\
)\end{array}$ & $\begin{array}{c}30 \\
(97)\end{array}$ & $\begin{array}{l}26 \\
(84 \\
)\end{array}$ & $\begin{array}{c}22 \\
(71 \\
)\end{array}$ & $\begin{array}{c}18 \\
(58 \\
)\end{array}$ & $\begin{array}{c}3 \\
(10 \\
)\end{array}$ & $\begin{array}{c}17 \\
(55 \\
)\end{array}$ & $\begin{array}{c}21 \\
(68 \\
)\end{array}$ & $\begin{array}{c}13 \\
(42 \\
)\end{array}$ & $\begin{array}{c}23 \\
(74 \\
)\end{array}$ & $\begin{array}{c}27 \\
(87 \\
)\end{array}$ & $\begin{array}{c}17 \\
(55 \\
)\end{array}$ & $\begin{array}{l}29 \\
(94 \\
)\end{array}$ & $\begin{array}{c}28 \\
(90 \\
)\end{array}$ \\
\hline & $\begin{array}{l}\text { OPD } \\
(n=6)\end{array}$ & $\begin{array}{c}6 \\
610 \\
0\end{array}$ & $\begin{array}{l}5 \\
(84 \\
)\end{array}$ & $\begin{array}{c}6 \\
(100 \\
)\end{array}$ & $\begin{array}{l}4 \\
(67 \\
)\end{array}$ & $\begin{array}{c}2 \\
(33 \\
)\end{array}$ & $\begin{array}{c}1 \\
(17 \\
)\end{array}$ & $\begin{array}{c}1 \\
(17 \\
)\end{array}$ & $\begin{array}{c}6 \\
610 \\
0\end{array}$ & $\begin{array}{c}6 \\
610 \\
0\end{array}$ & $\begin{array}{c}4 \\
(67 \\
)\end{array}$ & $\begin{array}{c}5 \\
(84 \\
)\end{array}$ & $\begin{array}{c}6 \\
(10 \\
0\end{array}$ & $\begin{array}{c}2 \\
(33 \\
)\end{array}$ & $\begin{array}{l}6 \\
(10 \\
0\end{array}$ & $\begin{array}{c}6 \\
610 \\
0\end{array}$ \\
\hline \multirow{2}{*}{ 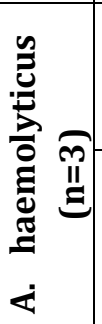 } & $\begin{array}{l}\text { ICU } \\
(n=2)\end{array}$ & $\begin{array}{c}1 \\
(50 \\
)\end{array}$ & $\mathbf{0}$ & $\mathbf{0}$ & $\begin{array}{c}1 \\
(50 \\
)\end{array}$ & $\begin{array}{c}2 \\
(10 \\
0\end{array}$ & $\mathbf{0}$ & $\mathbf{0}$ & $\mathbf{0}$ & $\mathbf{0}$ & $\mathbf{0}$ & $\begin{array}{l}2 \\
(10 \\
0\end{array}$ & $\begin{array}{c}1 \\
(50 \\
)\end{array}$ & $\mathbf{0}$ & $\begin{array}{c}1 \\
(50 \\
)\end{array}$ & 0 \\
\hline & $\begin{array}{l}\text { Indoo } \\
r \\
(n=1)\end{array}$ & $\begin{array}{c}1 \\
(10 \\
0\end{array}$ & 0 & $\mathbf{0}$ & $\mathbf{0}$ & $\begin{array}{c}1 \\
(10 \\
0\end{array}$ & $\mathbf{0}$ & $\mathbf{0}$ & $\mathbf{0}$ & $\mathbf{0}$ & $\mathbf{0}$ & $\begin{array}{l}1 \\
(10 \\
0\end{array}$ & $\begin{array}{c}1 \\
(10 \\
0\end{array}$ & $\mathbf{0}$ & $\begin{array}{c}1 \\
(10 \\
0\end{array}$ & $\begin{array}{c}1 \\
(10 \\
0\end{array}$ \\
\hline
\end{tabular}

*Figures in parenthesis represent percentage of susceptible strains 